Supporting Information

\title{
New material perspective for waste seashells by covalent functionalization
}

Giulia Magnabosco, Demetra Giuri, Anna Paola Di Bisceglie, Francesco Scarpino, Simona Fermani, Claudia Tomasini and Giuseppe Falini

Materials and Methods

page 2

Synthesis of the Rhodamine B -piperazine molecule

p. 3

Figure SI1. Particle size distribution of the oyster powder shell after ball milling

p. 4

Figure SI2. TGA profiles before (A) and after (B) the ball milling process

p. 4

Figure SI3. X-ray diffraction pattern and FTIR spectrum of the oyster shell powder

p. 5

Figure SI4. X-ray diffraction pattern and FTIR spectrum of the Rhod-B

covalently functionalized oyster shell powder

p. 5 


\section{Materials and Methods}

Oyster shells of Cassiopea gigas were kindly provided by Prof. Piero Addis of the University of Cagliari (Italy). The oysters were grown in the lagoon of San Teodoro (Italy, north-east Sardinia: $\left.40^{\circ} 48^{\prime} 38.08^{\prime \prime} \mathrm{N}, 9^{\circ} 40^{\prime} 26.99^{\prime \prime} \mathrm{E}\right)$.

First the shells were treated with a 5 vol. \% sodium hypochlorite solution for 24 hours and then carefully washed with deionized water. Once air dried, the shells were initially crashed with a crashing mill and then pulverized using a planetary ball mill (Pulverisette 6, Fritsch). $100 \mathrm{~g}$ of crashed oyster shell were added in the $\mathrm{ZrO}_{2}$ grinding jar with $300 \mathrm{~g}$ of grinding balls $(20 \mathrm{~mm}$ diameter, $\mathrm{ZrO}$ ). The mixture was milled for 2 hours at a speed of $750 \mathrm{rpm}$. Afterward, the grinding balls were separated and the product was isolated.

The Malvern Panalytical Mastersizer 2000 laser diffraction testing instrument was used to evaluate particle size distribution. The surface area (BET) of the oyster shell powder was measured using a Gemini VII Series Surface Area Analyzer (Micromeritics Instrument Corporation).

The scanning electron microscopy image were acquired using a Leica Cambridge Stereoscan 360 scanning electron microscope. The samples were gold coated $(2 \mathrm{~nm})$ before their observation.

A Thermo Scientific ${ }^{\mathrm{TM}}$ Nicolet ${ }^{\mathrm{TM}}$ iS $^{\mathrm{TM}} 10$ FTIR Spectrometer was used to collect the FTIR spectra. Disk sample for FTIR analysis was obtained by mixing a small amount $(<1 \mathrm{mg})$ of product with 100 $\mathrm{mg}$ of $\mathrm{KBr}$ and applying a pressure of $45 \mathrm{tsi}(620.5 \mathrm{MPa})$ to the mixture using a press. X-ray diffraction patterns were collected using a PanAnalytical X'Pert Pro diffractometer equipped with a multi-array $\mathrm{X}^{\prime}$ Celerator detector using $\mathrm{Cu} \mathrm{K} \alpha$ radiation generated at $40 \mathrm{kV}$ and $40 \mathrm{~mA}(\lambda=1.54056 \AA)$. The diffraction patterns were collected in the $2 \theta$ range between $20^{\circ}$ and $60^{\circ}$ with a step size $(\Delta 2 \theta)$ of $0.02^{\circ}$ and a counting time of $100 \mathrm{~s}$.

Confocal microscope images were collected using a Nikon A1R confocal microscope equipped with a laser diode (561 nm) and analyzed using the software imageJ, making a sum of the slides. Rhodamine has an excitation peak at $546 \mathrm{~nm}$ and an emission peak at $568 \mathrm{~nm} \cdot{ }^{1}$ A $561 \mathrm{~nm}$ laser for excitation and detected emission over the range 565-600 nm were used.

For the evaluation of the surface proteins on the surface of the powdered oyster shell the BCA method was used. A calibration curve was determined using different concentrations of the bovine serum albumin protein (BSA), reporting the different concentrations as a function of the maximum absorbance at $562 \mathrm{~nm}$ given by the absorption of the complex formed by the chelation of two molecules of $\mathrm{BCA}$ with a $\mathrm{Cu}^{+}$ion.

The amount of Rhodamine B on the two kind of powders was first investigated by UV-Vis spectroscopy (Ocean Optics UV-Visible Spectrophotometer). To perform the measurements, the powder was dissolved in a $50 \mathrm{mM}$ acetate buffer solution at $\mathrm{pH} 4.5$. A calibration curve was used. The absorption was measured at $558 \mathrm{~nm}$.

NMR spectra were recorded with a Varian Inova 400 spectrometer at $400 \mathrm{MHz}$. Chemical shifts are reported in $\delta$ values relative to the solvent peak. 


\section{Synthesis of the Rhodamine B - piperazine molecule}

A 2.0 M solution of trimethyl aluminium in toluene $(1.36 \mathrm{mmol}, 678 \mu \mathrm{L})$ was added dropwise to a solution of piperazine $(2.71 \mathrm{mmol}, 234 \mathrm{mg})$ in dry dichloromethane $(1 \mathrm{~mL})$ at room temperature and the mixture was stirred for 1 hour until a white precipitate was formed. A solution of rhodamine B lactone1 $(0.68 \mathrm{mmol}, 300 \mathrm{mg})$ in dry dichloromethane $(680 \mu \mathrm{L})$ was added dropwise to the heterogeneous mixture under inert atmosphere and gas evolution was observed during the addition period. After reacting under reflux for $24 \mathrm{~h}$, the reaction mixture was quenched by adding $0.1 \mathrm{M}$ aqueous $\mathrm{HCl}$ dropwise to the mixture until gas evolution ceased. The heterogeneous mixture was filtered and the retained solids were rinsed with dichloromethane $(10 \mathrm{~mL})$ and a 4:1 mixture of dichloromethane/methanol $(10 \mathrm{~mL})$. The combined liquid fraction was concentrated under reduced pressure, then dichloromethane $(15 \mathrm{~mL})$ was added to the residue and a heterogeneous mixture was obtained, that was filtered to remove the insoluble salts. The liquid phase was concentrated under reduced pressure, the resulting solid was dissolved in ethyl acetate $(5 \mathrm{~mL})$ and aqueous $\mathrm{NaHCO}_{3}(5$ $\mathrm{mL}$ ). The mixture was separated and the aqueous layer was washed with three additional portions of ethyl acetate $(10 \mathrm{~mL})$, saturated with $\mathrm{NaCl}$ and acidified with $1 \mathrm{M} \mathrm{HCl}$ until $\mathrm{pH} \approx 2$. The aqueous layer was extracted with a mixture of i-propanol/dichloromethane 2:1 $(3 \times 20 \mathrm{~mL})$, until a faint pink colour persisted. The combined organic layers were dried over sodium sulphate and concentrated in vacuo. Piperazine-rhodamine B was obtained in $52 \%$ yield $(0.36 \mathrm{mmol}, 210 \mathrm{mg})$ as a dark purple solid.

1 J. Coppeta, C. Rogers, Dual emission laser induced fluorescence for direct planar scalar behavior measurements. Experiments in Fluids, 1998, 25, 1-15. 


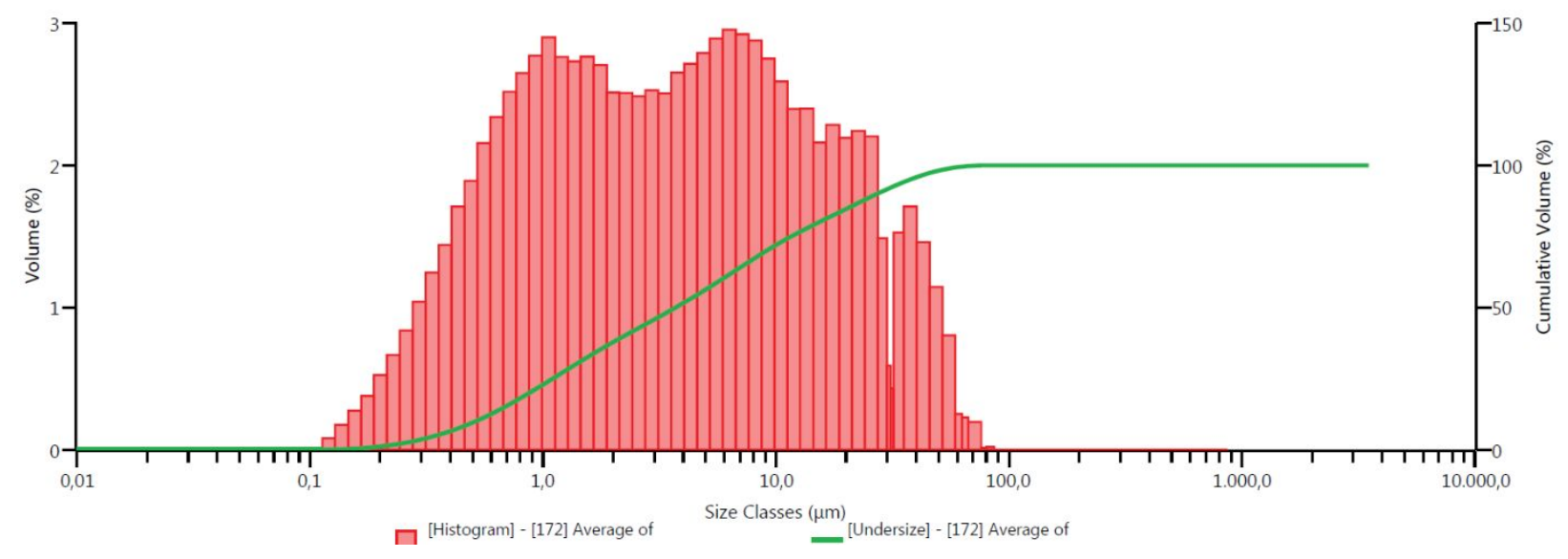

\begin{tabular}{|c|c|c|c|c|c|c|c|c|c|c|c|c|c|}
\hline \multicolumn{14}{|l|}{ Result } \\
\hline Size $(\mu \mathrm{m})$ & \% Volume Under & Size $(\mu \mathrm{m})$ & \% Volume Under & Size $(\mu \mathrm{m})$ & \% Volume Under & Size $(\mu \mathrm{m})$ & \% Volume Under & Size $(\mu \mathrm{m})$ & \% Volume Under & Size $(\mu \mathrm{m})$ & \% Volume Under & Size $(\mu \mathrm{m})$ & \% Volume Under \\
\hline 0.0876 & 0.00 & 0.405 & 6.67 & 1.88 & 36.57 & 8.68 & 68.91 & 32.0 & 92.64 & 98.2 & 100.00 & 352 & 100.00 \\
\hline 0.0995 & 0.00 & 0.461 & 8.38 & 2.13 & 39.08 & 9.86 & 71.66 & 35.4 & 94.17 & 106 & 100.00 & 400 & 100.00 \\
\hline 0.113 & 0.00 & 0.523 & 10.27 & 2.42 & 41.59 & 11.2 & 74.25 & 40.2 & 95.88 & 112 & 100.00 & 454 & 100.00 \\
\hline 0.128 & 0.08 & 0.595 & 12.43 & 2.75 & 44.07 & 12.7 & 76.65 & 45.7 & 97.34 & 127 & 100.00 & 516 & 100.00 \\
\hline 0.146 & 0.26 & 0.676 & 14.77 & 3.13 & 46.60 & 14.5 & 79.05 & 51.9 & 98.49 & 144 & 100.00 & 586 & 100.00 \\
\hline 0.166 & 0.53 & 0.768 & 17.28 & 3.55 & 49.11 & 16.4 & 81.21 & 58.9 & 99.29 & 164 & 100.00 & 666 & 100.00 \\
\hline 0.188 & 0.91 & 0.872 & 19.93 & 4.04 & 51.76 & 18.7 & 83.49 & 63.0 & 99.54 & 186 & 100.00 & 756 & 100.00 \\
\hline 0.214 & 1.43 & 0.991 & 22.70 & 4.59 & 54.47 & 21.2 & 85.68 & 67.0 & 99.77 & 200 & 100.00 & 859 & 100.00 \\
\hline 0.243 & 2.10 & 1.13 & 25.60 & 5.21 & 57.26 & 24.1 & 87.93 & 76.1 & 99.97 & 211 & 100.00 & & \\
\hline 0.276 & 2.94 & 1.28 & 28.37 & 5.92 & 60.16 & 27.4 & 90.13 & 80.0 & 99.98 & 240 & 100.00 & & \\
\hline 0.314 & 3.98 & 1.45 & 31.10 & 6.73 & 63.11 & 30.0 & 91.62 & 86.4 & 100.00 & 273 & 100.00 & & \\
\hline 0.357 & 5.23 & 1.65 & 33.86 & 7.64 & 66.03 & 31.1 & 92.21 & 90.0 & 100.00 & 310 & 100.00 & & \\
\hline
\end{tabular}

Figure SI1. Particle size distribution of the oyster powder shell after ball milling.
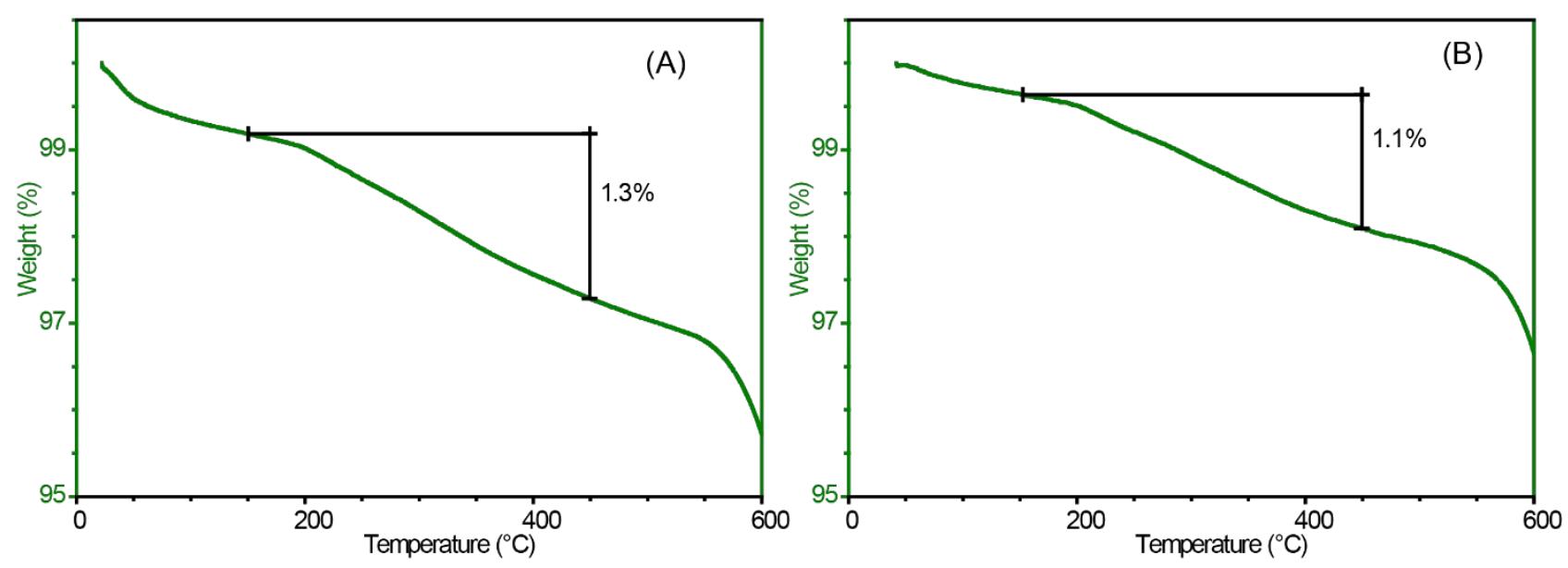

Figure SI2. TGA profiles before (A) and after (B) the ball milling process. 

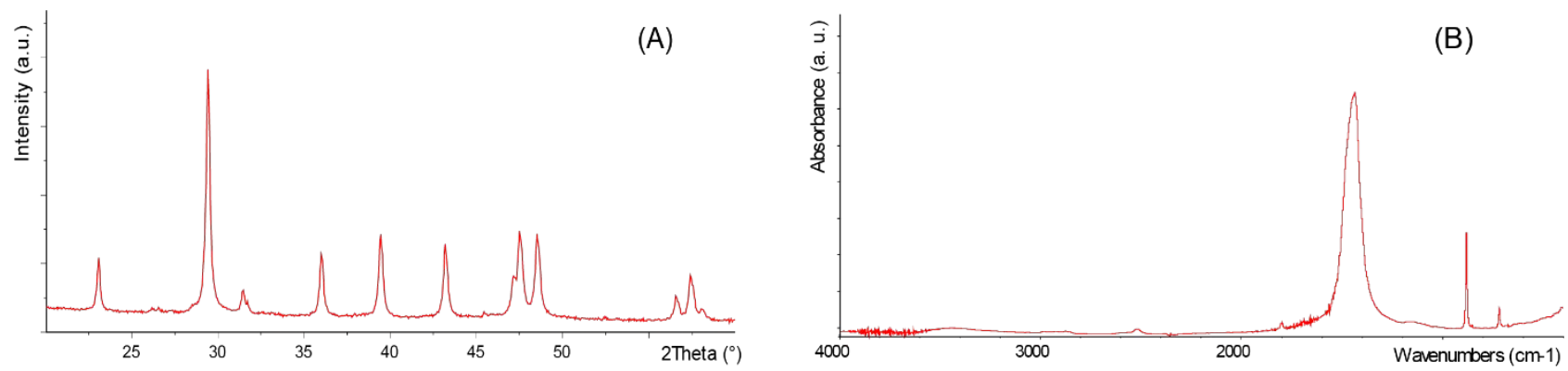

Figure SI3. (A) X-ray diffraction pattern of the oyster shell powder. Only the diffraction peaks due to $\mathrm{Mg}$ calcite are present. (B) FTIR spectrum of the oyster shell powder. Only absorption bands due to $\mathrm{Mg}$ calcite are present.
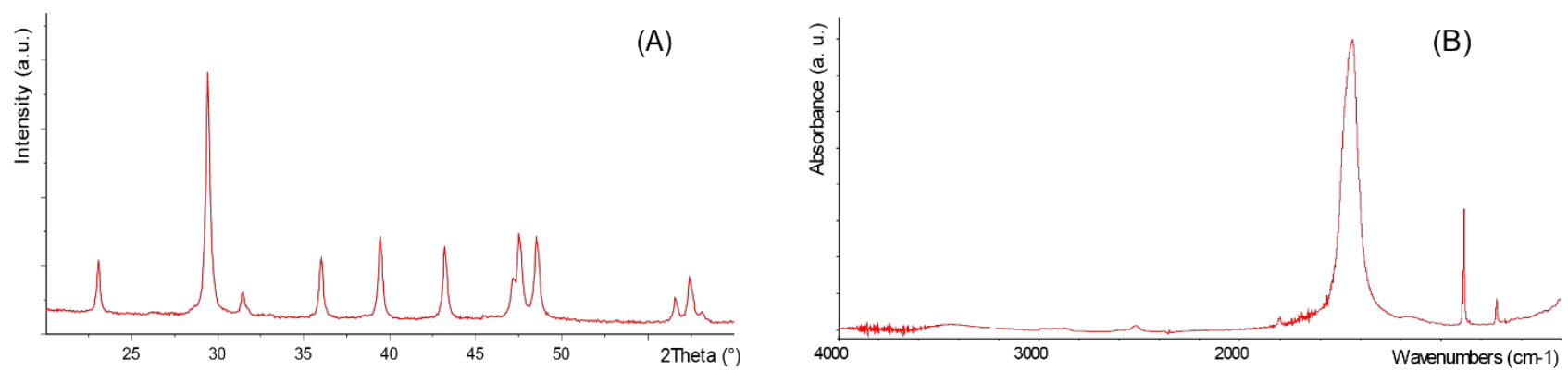

Figure SI4. (A) X-ray diffraction pattern of the Rhod-B covalently functionalized oyster shell powder. Only the diffraction peaks due to Mg calcite are present. (B) FTIR spectrum of the Rhod-B covalently functionalized oyster shell powder. Only absorption bands due to $\mathrm{Mg}$ calcite are present. 